\title{
Reperfusion Therapy in Very Elderly with Acute Ischemic Stroke
}

\author{
Michelle P Lin* \\ Department of Neurology, Johns Hopkins University School of Medicine, USA
}

Submission: June 16, 2017; Published: July 31, 2017

*Corresponding author: Michelle P Lin, MD, MPH, Department of Neurology, Johns Hopkins School of Medicine, $600 \mathrm{~N}$ Wolfe Street. Phipps Building, Suite 486, Baltimore, Maryland 21287, USA, Tel: 410-955-2228; Fax: 410-955-0793; Email: michelle.py.lin@gmail.com

\begin{abstract}
Background: Very elderly (age $\geq 80 y 0$ ) individuals account for about one-third of all stroke admissions with mixed literature demonstrating relative poor stroke outcomes. With overwhelming recent evidence supporting the use of intra-arterial thrombectomy in addition to IV thrombolysis for large-vessel occlusive stroke, we conducted a pool analysis to assess long-term functional outcome following mechanical thrombectomy in very elderly.
\end{abstract}

Methods: Stroke endovascular trials published in New England Journal of Medicine 2015 were included if they reported odds ratio of good functional outcome (improvement in modified Rankin score, mRS) comparing thrombectomy vs IV-tPA dichotomized by age groups (age $\leq 80 \mathrm{yo}$ vs $>80 \mathrm{yo}, 2$ studies dichotomized age at 70yo). Multivariate adjusted odds ratios and the corresponding standard errors were used for the metaanalysis. The pooled estimates with $95 \%$ confidence interval were compared between elderly and younger age groups. Forest plots constructed.

Results: Of the five endovascular thrombectomy trials, 4 studies reported subgroup analysis by age with 1,206 participants, 28\% (N=334) were above the age of $80 \mathrm{yo}, 72 \%(\mathrm{~N}=872)$ were $\leq 80 \mathrm{yo}$. Among very elderly patients undergoing thrombectomy, the pooled odds ratio of good functional outcome at 3 months was 1.91 (1.13-3.24), in the younger group the pooled odds ratio was 1.95 (1.50-2.53).

Conclusion: Endovascular therapy was an effective therapy for very elderly individuals presenting with acute ischemic stroke caused by large vessel occlusive disease. Future studies are needed to further assess the safety and effectiveness of thrombectomy in this growing population.

Keywords: Thrombectomy; Thrombolysis; Elderly; Pooled analysis

\section{Introduction}

People older than 80 years of age represent the fastest growing segment of the population in developed countries, and account for more than a third of stroke admissions. While intravenous tissue plasminogen activator (IV-tPA) and endovascular thrombectomy (EVT) have Class 1 level of evidence for the treatment of acute ischemic stroke [1,2], the debate continues about the use of acute reperfusion therapy in older patients given concerns for age-related comorbidities and functional fragility. In this brief review article, we will discuss the effectiveness and safety of acute reperfusion therapy in elderly individuals with acute ischemic stroke.

\section{Intravenous thrombolysis in elderly}

Robust data support the use of intravenous thrombolysis in patients younger than 80 years of age within 4.5 hours of stroke onset. 3 Contemporary studies with good representation of elderly individuals also support the use of intravenous thrombolysis in this population [3,4]. The International Stroke Trial (IST-3) is one of the largest, randomized thrombolysis trial with more than half of the patients $(53 \%)$ were older than 80 years of age to evaluate the benefits and harms of IV-tPA in extended window up to 6 hours of stroke onset [5]. Contrary to the expectations that elderly group may have poorer 6 months functional outcome, the study showed that patients 80 years of age or older had greater benefit than their younger counterparts. The adjust odds ratio (OR) of good functional outcome at 6 months comparing IV-tPA vs placebo among elderly >80yo was 1.35 (95\% confidence interval [CI] 0.97-1.88, compared to younger group $\leq 80$ yo was 0.92 (95\% CI 0.67-1.26).

Emberson et al. [4] conducted an individual-level metaanalysis from nine randomized control thrombolysis trials to assess the effect of age, treatment delay, and stroke severity on the effects of IV-tPA for acute ischemic stroke [4]. The study included 6,756 patients ( $26 \%$ were elderly 80 years or above), 
defined good stroke outcome as no significant disability at 3-6 months (modified Rankin Score of 0 or 1 ) and defined sICH within 7 days using the SITS-MOST definition. Authors found that IV-tPA significantly increased the odds of a good outcome, with earlier treatment resulting in significantly greater proportional benefit ( $p=0.016$ for trend of increasing proportional benefit with earlier treatment). Importantly, age did not change the effect of IV-tPA on odds of a good outcome ( $p=0.53)$. The effect of IV-tPA was similar for patients aged 80 years or younger (39\% vs $34 \%$, OR $1.25,95 \%$ CI $1.10-1.42, \mathrm{p}<0.0001$ ) and for those older than 80 years $(18 \%$ vs $13 \%$, OR $1.56,95 \%$ CI $1.17-2.08$, $\mathrm{p}=0.0023$ ).

Unfortunately, very elderly individuals not uncommonly have contraindications that preclude them from receiving IVtPA such as being on anticoagulation for atrial fibrillation. There is also concern forincreased risk of symptomatic intracranial hemorrhage (ICH) after thrombolysis from agerelated conditions such as cerebral microbleeds (CMBs) from hypertensive or cerebral amyloid angiopathy. A meta-analysis of 10 studies including 2,028 patients treated with IV-tPA showed that patients with CMBs had higher risk of symptomatic ICH after thrombolysis (8.5\%; 95\% confidence interval [CI]: 6.1\%-11.4\%) compare with those without CMBs (3.9\%; 95\% CI: 3\%-5\%) without CMBs. The pooled OR of ICH was 2.26 (95\%CI: 1.463.49; $\mathrm{p}<0.0001$ ) [6]. Given the age-related comorbid conditions that may preclude elderly individuals from receiving IV-tPA, we explored the effectiveness of thrombectomy in very elderly individuals. It remains unclear whether the outcome of elderly individuals treated with endovascular treatment is better than for those who do not undergo thrombectomy.

\section{Endovascular thrombectomy in elderly}

In this study, we performed a pooled analysis of stroke endovascular trials published in New England Journal of Medicine in 2015 that reported odds ratio of good functional outcome at 3 months (improvement in modified Rankin score, mRS) comparing thrombectomy vs IV-tPA dichotomized by age groups (age $\leq 80$ yo vs $>80$ yo, 2 studies dichotomized age at 70yo). Multivariate adjusted odds ratios and the corresponding standard errors were used for the meta-analysis. The pooled estimates with $95 \%$ confidence interval were compared between elderly and younger age groups.

We found that of the five endovascular thrombectomy trials, 4 studies reported subgroup analysis by age with 1,206 participants, $28 \%(\mathrm{~N}=334)$ were above the age of 80 yo, $72 \%$ $(\mathrm{N}=872)$ were $\leq 80$ yo. Among very elderly patients undergoing thrombectomy, the pooled odds ratio of good functional outcome at 3 months was 1.91 (1.13-3.24), in the younger group the pooled odds ratio was 1.95 (1.50-2.53). Figure 1 shows the Forest Plot.

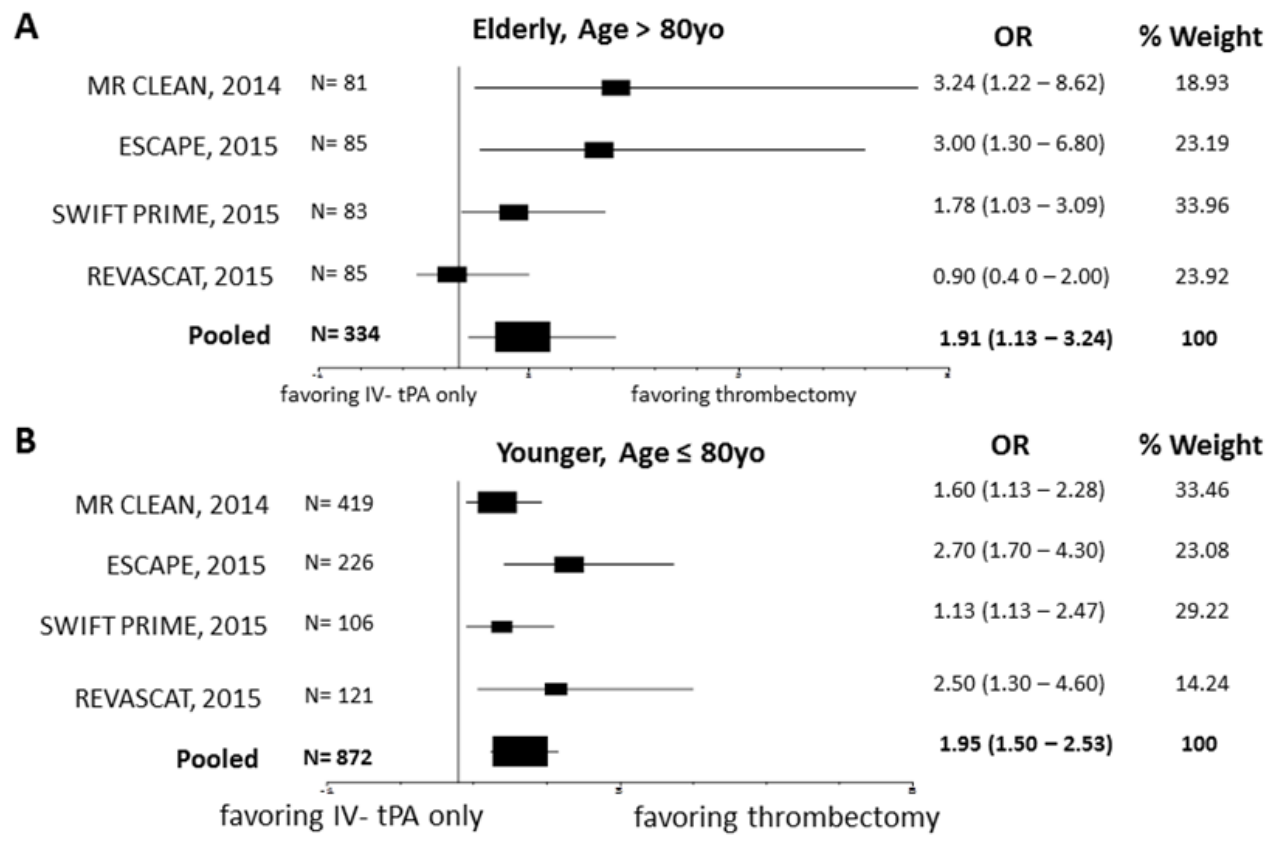

Figure 1: Adjusted odds ratio of improvement in modified Rankin Score (mRS) at 90 days, stratified by age.

Five randomized trials published in 2015 demonstrated the safety and effectiveness of endovascular thrombectomy (EVT) for the treatment of large-vessel occlusive ischemic stroke within 6 hours of symptom onset [7-11]. Similarly, HERMES study is a meta-analysis of individual patient data from the five randomized trial [12]. The analysis included 1287 patients 
randomized to receive EVT vs standard of treatment (ie. IVtPA). Mechanical thrombectomy significantly reduced disability at 90 days compared with control (OR 2.5, 95\% CI 1.76-3.53; $\mathrm{p}<0.0001$ ). The number needed to treat with EVT to reduce disability was 2.6 . In subgroup analysis by age, authors showed no difference in outcome suggesting that EVT is effective in very elderly individuals aged 80 years or older (OR 3.68, 95\% CI 1.95-6.92). Mortality at 90 days and sICH did not differ between groups [12].

\section{Conclusion}

Older age continued to be a common exclusion criterion in contemporary clinical trials assessing acute reperfusion therapy. Indeed 2 of the 5 trails included in the current analysis had an upper age limit of 80yo (SWIFT-PRIME, REVASCAT). Nevertheless, pooled meta-analysis of high-quality randomized control trials for EVT support the use OF EVT within 6 hours of stroke onset in elderly individuals above the age of 80 years without significant increase in symptomatic intracranial hemorrhage compared to their younger counterpart. While the population burden of stroke associated with ageing is rapidly rising, there is clearly a need for prospective trials looking for the optimal acute reperfusion therapy options for elderly individuals.

\section{References}

1. Jauch EC, Saver JL, Adams HP, Bruno A, Connors JJ, et al. (2013) Guidelines for the early management of patients with acute ischemic stroke: A guideline for healthcare professionals from the american heart Association/American Stroke Association. Stroke 44(3): 870947

2. Powers WJ, Derdeyn CP, Biller J, Coffey CS, Hoh BL, et al. (2015) american heart association/american stroke association focused update of the guidelines for the early management of patients with acute ischemic stroke regarding endovascular treatment: A guideline for healthcare professionals from the American Heart Association/ American Stroke Association. Stroke 46(10): 3020-3035.

3. Lees KR, Emberson J, Blackwell L, Bluhmki E, Davis SM, et al. (2016) Effects of alteplase for acute stroke on the distribution of functional outcomes: A pooled analysis of 9 trials. Stroke 47(9): 2373-2379.

4. Emberson J, Lees KR, Lyden P, Blackwell L, Albers G, et al. (2014) Effect of treatment delay, age, and stroke severity on the effects of intravenous thrombolysis with alteplase for acute is chaemic stroke: A meta-analysis of individual patient data from randomised trials. Lancet 384(9958): 1929-1935.

5. Arauz A, Berge E, Sandercock P (2014) Third International Stroke Trial 3: An update. Curr Opin Neurol 27(1): 8-12.

6. Charidimou A, Shoamanesh A, Wilson D, Gang Q, Fox Z, et al. (2015) cerebral microbleeds and postthrombolysis intracerebral hemorrhage risk updated meta-analysis. Neurology 85(11): 927-924.

7. Goyal M, Demchuk AM, Menon BK, Eesa M, Rempel JL, et al. (2015) Randomized assessment of rapid endovascular treatment of ischemic stroke. N Engl J Med 372: 1019-1030.

8. Saver JL, Goyal M, Bonafe A, Diener HC, Levy EI, et al. (2015) Stentretriever thrombectomy after intravenous t-PA vs. t-PA alone in stroke. N Engl J Med 372: 2285-2295.

9. Jovin TG, Chamorro A, Cobo E, de Miquel MA, Molina CA, et al. (2015) Thrombectomy within 8 hours after symptom onset in ischemic stroke. N Engl J Med 372: 2296-2306.

10. Berkhemer OA, Fransen PS, Beumer D, van den Berg LA, Lingsma HF et al. (2015) A randomized trial of intraarterial treatment for acute ischemic stroke. N Engl J Med 372: 11-20.

11. Campbell BC, Mitchell PJ, Kleinig TJ, Dewey HM, Churilov L, et al. (2015) Endovascular therapy for ischemic stroke with perfusionimaging selection. N Engl J Med 372: 1009-1018.

12. Goyal M, Menon BK, van Zwam WH, Dippel DW, Mitchell PJ, et al. (2016) Endovascular thrombectomy after large-vessel ischaemic stroke: A meta-analysis of individual patient data from five randomised trials. Lancet 387(10029): 1723-1731.

\section{Your next submission with Juniper Publishers will reach you the below assets}

- Quality Editorial service

- Swift Peer Review

- Reprints availability

- E-prints Service

- Manuscript Podcast for convenient understanding

- Global attainment for your research

- Manuscript accessibility in different formats

( Pdf, E-pub, Full Text, Audio)

- Unceasing customer service

Track the below URL for one-step submission https://juniperpublishers.com/online-submission.php 